\title{
The interactive education in teaching languages: microblogging as the way to improve postgraduate students' communicative interaction in English
}

\author{
Aida R. Nurutdinova - Elena V. Dmitrieva - Elena A. Nelyubina - Liliya R. \\ Nurova - Kira R. Wagner
}

DOI: 10.18355/XL.2018.11.02.10

\begin{abstract}
Currently, a high proficient level in a foreign language is one of the criteria by which the qualified specialist is assessed. Under given conditions of economic and world politics, Russia actively participates in the world community life and expands its international relations. These factors determine the increased demand for teaching foreign languages. The use of computers becomes the integral part of the learning process, and its use in the teaching ESL opens up new opportunities for educators and leaners in their studies and allows solving fundamentally new tasks in the methodology of teaching a foreign language. In the framework of the education system, the computer technologies in the educational process is being actively implemented. The research states the use of Web 2.0 services, and microblogging, in particular, in the process of teaching foreign languages, is an indispensable resource for the formation of communicative skills of students. The presented research paper examines the microblogging as the additional interactive technology for teaching foreign languages and as the effective tool for building the communication skills of postgraduate students of non-linguistic Universities. Due to the fact that the term "interactive learning" is increasingly used in the field of information technology, distance education, use of Internet resources and work online, the authors will consider the main aspects of the computer linguodidactics development as a basic branch of knowledge, responsible for the development of interactive learning ESL. The results of the research are possible to use in the course of the methodology of teaching foreign languages, in developing teaching aids and courses in foreign languages.
\end{abstract}

Key words: computer technology, second language acquisition, communicative skills, interactive technology, non-linguistics universities, interactive learning, interactive software environment

\section{Introduction}

In the days of the USSR, the most popular method of teaching a foreign language was a grammar-translation or traditional method, in which students were mainly taught reading and translating of foreign texts using a dictionary. In the process of using this method, the formation of communication skills was not the goal of training (Bovtenko, 2005; Gal'skova, 2001; Furmanov, 2003; Scholefield, 1997). Thus, the communication in a foreign language was extremely problematic, due to the language barrier that arose from the fact that in the process of learning a foreign language, students did not learn a foreign language, but only received theoretical information about its structure. Knowledge in grammatical rules and the ability to translate foreign texts are insufficient conditions for successful communication in a foreign language. This led to the need to revise the goals, objectives, and content of foreign language teaching, as well as to change the teaching methods and control forms.

According to the Federal State Educational Standard (Federal Law № 273-FZ), higher professional education in the Russian Federation is based on a competence approach, which implies the formation of certain professional and general educational competencies among students, which also includes communicative competence, that 
is, mastering a foreign language as a means of business communication. The development of this competence is the main goal of teaching a foreign language in a university. In connection with the new FGOS implementation, the aims of education were revised (Nurutdinova et al., 2016a).

Previously, the goal was the skills development, and now the new type of personality is becoming in demand with the following competencies: social, including the skills of tolerance manifestation in interpersonal communication; communicative, as the main competence, formed in the study of ESL; information, including skills with working information resources; self-educational, realizing the desire to learn all their life (Botvenko, 2005; Masalimova, Shaidullina, Usak, 2016).

One of the requirements for the implementation of any basic educational programs (BEP) of the bachelor and master's degree is the wide use of active and interactive forms of conducting classes in the learning process in combination with extracurricular activities with the formation and development of professional skills. The proportion of sessions conducted in interactive forms is determined as the main goal, the peculiarity of the learners' contingent and the content of specific disciplines. In general, they should constitute at least 20 percent of lectures hours in most areas of university training (Federal Law № 273-FZ).

The object is the process of teaching foreign languages in non-linguistic universities for postgraduate students.

The subject is the interactive technology of teaching foreign languages for postgraduate students through the service of microblogging.

The aim is to develop an additional interactive technology for postgraduate students for teaching foreign languages in non-linguistic universities with the use of the microblogging service.

The objectives are: to study modern methods of teaching foreign languages in Universities for postgraduate students; to review and compare active and interactive teaching methods; to study information and computer technologies used in the teaching of foreign languages; to reveal the didactic advantage of using the microblogging service in teaching foreign languages.

\section{Literature Review}

We review and analyse the additional literature on second language learning. There has been the meaningful volume of research done on second language instructions (techniques, approaches) in Russia, discussing the mentioned aspects, which may imitate or impede Russian learners to acquire the English language including internalization, culture, teachers' training limitations, traditional instructions and students' perception toward English instructions. The given research is not sufficiently developed within the framework of the Russian educational community. At the moment there are several works devoted to teaching foreign languages through microblogging L. Qiu and A.K. Leung (2010), M. Sample (2010).

The theoretical basis of the research work was the work of both Russian authors: L.A. Artamonova et al. (2012), O.I. Donetskaya (2009), E.S. Polat (2001), S.B. Stupina (2009), P.V. Sysoev (2009, 2012, 2016), M.A. Bovtenko (2005), and foreign ones: S.B. Barnes (2003), G. Dudeney, N. Hockly (2007), B. Godwin -Jones (2003), J.R. Young (2008), W. Scholefield (1997).

The terms "interactivity", "interactive learning", "interactive methods and teaching methods" have been analysed in the research articles and works of the following academicians: B.C. Badmaev (1999), E.V. Korotaeva (2012), A.G Tikhobaev (2012). These documents on the policy issues of higher education (Order of The Ministry of Education and Science of the Russian Federation of December 19, 2013, № 1367; The Russian Federation Government Resolution dated 9 April 2010, №218, №219, №220; Order of The Ministry of Education and Science of the Russian Federation of

XLinguae, Volume 11, Issue 2, April 2018, ISSN 1337-8384, eISSN 2453-711X 
December 19, 2013, № 1367; Federal Law № 273-FZ) on the whole and particularly in Russia.

The literature review includes different kind of sources as official statistics, reports, scholarly journals, reviewed articles, reference books, research institutions reports on higher education integration, national and international universities libraries, computerized databases, the WWW.

\section{Methodological Bases and Research Methods}

Methodological basis of the presented research study is the system approach including system and complex, systemic-structural and systemic-functional approaches. The purpose and problems of the research have defined the choice of methods of the analysis.

The choice of its methods can be determined by the object of study, to which we refer the language of the city in terms of its functioning in the communication processes.

In work, such research procedures as hypothetical-deductive method, inductive method, descriptive and comparative method, definition analysis, elements of cognitive interpretation are used.

The descriptive method involves observance of certain requirements: a clear understanding of the subject matter chosen, description sequence, ordering, grouping or classification, material characteristics (qualitative, quantitative) in accordance with the research objectives.

We can highlight the following group of methods: the general scientific methods are represented by the following kinds: systematic approach (to analyse and synthesize theoretical and empirical materials); the dialectical approach allows addressing the causes of contradictions; the generalization approach is required throughout the study for the formulation of conclusions and allows us to generalize and systematize the study of theoretical and empirical material; the induction method is used to study the induction of theoretical and empirical information at all stages of the research; the deduction method enables the transition from general to specific provisions of the findings and phenomena.

Accumulation and generalization of the experience of integration in higher education had always been distinguished by a high scientific and fundamental, active participation in international processes, including the field of scientific comparative studies. The methods used in the presented research paper include analysis of literature, the study of monographic publications, scientific articles, and papers on the research problem.

Besides, in our research content analysis methods were applied to the identification of the substantial party of texts of mass media. The discourse analysis, studying structure and units of discourse, basic of which is the speech act, and the integrated approach to the analysis of mass media texts consisting in studying of their semantics, pragmatics, syntactic with use of the component, contextual and stylistic analysis were realized.

The material was identified mainly by reference searching and electronic literature searching using as search terms higher education, rationales for higher education integration, etc.

\section{Results}

\subsection{Computer and Network Technologies: the Computer Linguodidactics in the ESL Teaching}

Computer linguodidactics is one of the most intensively developing areas of teaching methodology for a foreign language. Since the mid-80s, it has undergone a number of changes, closely related to the development of computer technology and the concept of language learning. The opportunities that are provided by modern information technologies are significant for teaching the language. 
The theory of teaching foreign languages is also undergoing significant changes under the influence of new information technologies which create conditions for the full implementation of the basic didactics principles, such as visibility, accessibility, feasibility, consciousness, and activity while changing the course of the educational process. Currently, the introduction of computers, multimedia technologies, and the Internet influences the education system, causing significant changes in the content and methods of teaching foreign languages. The computer is widely used as a tool for working with information. When using a computer, verbal communicative activity is considered in three aspects:

1.Communication in real time using e-mail and information networks;

2.Interactive dialogue between the learner and the computer, in which man-machine dialogue is carried out.

3.Learners' Interaction with computer training programs.

The possibility of using a computer in class for a foreign language is determined by the specifics of the academic discipline. The leading component of the teaching content is teaching various types of speech activity: speaking, listening, reading, writing. Teaching computer programs are simulators that help to organize the independent work and create the valuable conditions under which learners practice their knowledge (Donetskaya, 2009).

The use of multimedia facilitates the realization of the person-oriented approach in teaching, provides individualization and differentiation, taking into account the characteristics of learners. Training with the help of a computer makes it possible to organize the independent work of each learner (Galushkin, 2017a,b). The selection of training programs depends on the educational material and the learning level of postgraduate students. In addition, the computer can completely eliminate one of the most important reasons for the negative attitude towards learning - failure, due to a lack of material understanding or a problem in knowledge. It is this aspect that is provided by the authors of numerous computer training programs. Working on the computer, the learners gets the opportunity to complete the solution of the problem to the end, relying on the necessary help.

The advantages of introducing Internet technologies into the learning process of a foreign language are no longer in doubt. The influence of various forms of synchronous and asynchronous Internet communication on the communicative competence formation is also positive. The network resources are an invaluable basis for creating an information-objective environment, education, and self-education, meeting the personal and professional interests and needs.

However, access to Internet resources alone does not guarantee fast and high-quality language education. Methodically illiterate learners' work with Internet resources can form false stereotypes and generalizations about the culture of the country of the studied language, even racism, and xenophobia (Furmanov, 2003).

Educational Internet resources should be aimed at the integrated formation and development: aspects of communicative competence in another language, including its components; linguistic, sociocultural, sociolinguistic, discursive, strategic, educational and cognitive; communicative-cognitive skills search and selection, product analysis and synthesis of information received; communicative skills of presenting and discussing the work results with Internet resources; the ability to use the resources of the Internet for self-education in order to get acquainted with the cultural and historical heritage of various countries and peoples, and also act as a representative of the native culture, country, city; skills to use the network resources to meet their information and educational interests and needs.

In the didactic strategy, the Internet includes two main components: forms of telecommunications (e-mail, chat, forum, ICQ, video and web conferences) and information resources. Initially, they were created for real communication between

XLinguae, Volume 11, Issue 2, April 2018, ISSN 1337-8384, eISSN 2453-711X 
people who are on the distance from each other, and now they are widely used in teaching a foreign language.

There are five types of Internet teaching resources in the English literature:

1.Hotlist - the list of sites with resources on the topic being studied; for creating the hotlist all you need is to enter the keywords into the search engine.

2.Multimedia scrapbook/draft - the collection of multimedia resources, unlike the hotlist, in the scrapbook, in addition to text links, there are photos, audio files, and video clips, graphics information, animated virtual tours. These files can be easily downloaded by learners and used as informative or illustrative material in the study of the particular topic.

3.Treasure hunt - contains questions about the content of each site: the educator directs the search and cognitive activity of the learners. The learners are asked one more general question on a complete understanding of the factual material.

4.The sample's subject is the next step in complexity compared to the Treasure hunt. Also contains links to text and multimedia materials on the Internet. After studying each aspect of the topic, students need to answer the questions posed, but the questions are not directed at the actual study of the material (as in the previous case), but for discussion of discussion topics. Students need not only to get acquainted with the material but also to express and argue their opinion on the discussed debatable issue.

5.Internet project - the most complex type of training through the project activities on any topic using the resources of the Internet. It includes all the four above-mentioned components.

Each of the given types follows the previous one, gradually becoming more complicated, thereby allowing to solve more complex educational tasks. The first two are aimed at finding, selecting and classifying information. The rest contain elements of problem training and are aimed at enhancing the search and cognitive activity of learners. The introduction of educational Internet resources in the learning process promotes the development of communicative skills of learners. The complexity of the material and its volume vary and should correspond to the learners' progress level at each stage of training.

The methodical potential of the learning through Intent-resources allows:

- choose text, graphics, photo, audio and video materials according to the topics;

- organize in groups the discussion of cultural and social problems;

- linguistic analysis of native speakers' speech (representatives of various social groups, dialects, and accents);

- organize extracurricular and extra-curricular project activities;

- create favourable conditions for learners with a high level of foreign-language communicative competence to realize their intellectual potential (Gal'skova, 2001; Zagvyazinsky, Atakhanov, 2005; Passov, 1985).

The use of ICT is now an integral part of the teaching and upbringing process, contributes to the modernization of higher education, allows for an activity-based approach to learning and successfully forms the communicative and informational competencies of learners (Nurutdinova, Dmitrieva, 2018). Competently using the information resources of the Internet, the educators can more effectively solve the number of didactic tasks during the lectures (workshops, seminars):

- to form reading skills, directly using the network materials of changing degrees of complexity;

- to improve listening skills on the basis of authentic texts on the Internet;

- to improve the monologue and dialogue skills on the basis of the problematic discussion of network materials;

- to replenish learners' vocabulary with the vocabulary of the foreign language that reflects a certain stage in the culture development, the social and political structure; 
- to get acquainted with the cultural knowledge, including speech etiquette, especially the speech behaviour of different people in the conditions of communication, peculiarities of culture and traditions (Sysoev, 2010; Sysoev, 2012).

\subsection{The Resource for Teaching Reading and Writing}

Currently, the use of blogs for educational purposes is widespread. This activity relates to asynchronous network communications, which gives the students the opportunity to think in advance of the answer.

During the asynchronous communication, the following tasks are performed: development of the rules of telecommunications etiquette adopted on The Internet; formation of reading skills; improving the listening skills; creation of joint creative projects; formation of stable motivation for students to study in English; support and establishment of business contacts and contacts with their peers in English-speaking countries; improving the skills of using the Internet network (Barnes, 2003).

According to S.B. Barnes (2003), R. Godwin-Jones (2003), A.R. Nurutdinova, E.V. Dmitrieva et al. (2016) in the educational process, there are three types of blogs used in the educational process.

1.Educator's blog. This type of blog is created and managed directly by the educator. A blog can contain personal information about interests, travel, family and so on. In this case, this blog will serve as a learning model for creating your own blogs. However, a more popular option for using a teacher's blog is to post course information, which usually includes:

- course program and homework; information on the material studied;

- recommended sources for independent study (reading and listening in a foreign language); links to information and reference Internet resources;

- links to educational Internet resources on the topics studied.

The similar content of the educator's blog is the useful source for clarifying the homework and getting links to additional sources for out-of-class work. Such work with the blog of the educator promotes the development of learner's reading skills in a foreign language. In this case, the blog acts as a functional type of text, based on which learners can develop the following reading skills: to provide the necessary facts/information; extract necessary/interesting information; evaluate the importance of information.

\section{Personal learners' blogs}

When you run your own blog in a foreign language, learners can submit personal information: about the date and place of birth, their family, hobbies, interests, friends, achievements, links to favourite Internet sites, photos and videos. Learners weekly add new information and get to know fellow class blogs and comment on the information posted in them. When working with personal blogs, students develop the following language skills:

- writing skills: the use of the necessary language facilities for submission to the writing personal information; the use of the necessary linguistic means by which it is possible to represent the country and/or the city and culture in a foreign language environment; the use of the necessary language tools for expression opinions, manifestations of consent/disagreement in a non-categorical and 50 non-aggressive form (when commenting on blogs of classmates or teacher); the argumentation of their point of view.

- reading skills: to provide the necessary facts/information; to provide extract necessary/interesting information; to assess the importance of information.

3.Blog of the training group. Unlike personal blogs, each of which is located on a separate page, in the blog of the training group the students' comments are placed on one page one after another, which greatly facilitates acquaintance with the opinions of 
others and stimulates discussion. When working with the blog of the training group, learners develop the following skills:

- writing skills: to state the content of the writing by using short messages; use the necessary language tools for expressing opinions, manifestations of consent/disagreement in the non-categorical and non-aggressive form; make analogies, comparisons, comparisons available language tools; argue their point of view using language tools.

- reading skills: to provide the necessary facts/information; to separate the main information from the secondary information; to determine the temporal and causeeffect relationship between events and phenomena; to generalize the described facts/phenomena; to evaluate the importance/novelty/reliability of information (Romantsova, 2014; Sysoev, 2012).

Thanks to the use of blogs in the learning process, unique conditions for teaching learners the written speech. Learners develop the skills of writing a personal letter, presenting information about themselves in the form adopted in the country of the studied language (autobiography, summary), talk about individual facts of their lives, expressing their attitude; describe their plans for the future. All this fully corresponds to the requirements of the modern educational standard for a foreign language.

The use of blog technology in the classroom for ESL intensifies interest in the learning process, it allows to carry out not only educational but also real communication in the studied language. The motivation in the use of blogs and microblogging is due not only to technological opportunities but also to the fact that learners write about what is important personally for them. They manage the process of their learning, actively searching for information necessary for them at the ESL and receiving comments from other people (Sysoev, 2012).

\section{Discussion}

\subsection{Theoretical Research Base: Contemporary Ideas Concerning the Prevailing Models of Linguistic Education in Higher Education}

The modern trends in the development of the world educational process include the use of new educational technologies in the learning process. The creation of modern educational concepts, as well as the recognition by the Bologna Convention the need for students to develop the desire for continuous self-education throughout their lives, leads to the use of interactive learning technologies for ESL/EFL that meet the following requirements:

- to increase the efficiency and quality of training;

- to provide motivations for independent cognitive activity;

- to develop the interdisciplinary ties (Donetskaya, 2009; Levitis, 1998; Sysoev, 2009).

Recently pedagogy has been interacting with related sciences, expanding its interdisciplinary relations, and these changes led to the appearance of the term "interactive learning".

The interaction concept was in fact borrowed from sociology, according to the categorical apparatus of which, interactive devices are called special devices or means that provide continuous user's interaction with the computer in the form of a dialogue. There were interactive polls, programs on radio and television, in which "live" conversations with listeners or spectators occur (Nurutdinova et al., 2017).

The postgraduate learners become a full participant in the educational process, the experience is the main source of educational knowledge and the educator, in turn, plays the role of a guide who doesn't provide knowledge in the finished form.

In prevailing methods, there are several learning models: passive, when the student acts as an "object" of learning ( $\mathrm{s} /$ he listens and looks); active, when the student acts as a "subject" of learning (independent work, creative tasks); interactive, in which the student interacts not only with educator but also with other students (inter (reciprocal), 
act (act)). The criterion for such classification is the interaction level of participants in the educational process.

\section{A passive learning model}

A passive learning model is the interaction form between the educator and the postgraduate learners, in which the learner acts as the object of learning activity, while the educator is the main character of the activity. The learners don't interact with each other. A lesson, a lecture, and an optional lesson can be included in this form of education (Leontiev, 1991). With these forms, the educator interacts with learners through interviews, control tasks, and tests. From the point of view of modern pedagogical technologies and the effectiveness of learners' mastery, the passive learning model is ineffective. However, it can have positive characteristics, such as an easy-toprepare training for the educator and the ability to cover teaching material in a timelimited environment.

\section{An active learning model}

An active learning model is the form of interaction between an educator and a learner, in which the learner becomes the subject of the educational activity to a greater extent, actively interacts with the educator during the lesson. The learner and the educator have equal rights. Active teaching methods presuppose the use of the methodical approaches system in educational activity, which is directed mainly not at the educator's presentation of finished knowledge and their reproduction, but on the independent mastery of knowledge by learners in the process of active cognitive activity (Leontiev, 1991).

There are different activity levels: the reproduction activity, which is characterized by the trainee aspirations, remember, reproduce knowledge, master the application methods; the interpretation activity, which is connected with the learner's desire to comprehend the studied meaning, to establish connections, to master the ways of applying knowledge of the changed conditions; creative activity presupposes the learner's aspiration to the theoretical knowledge comprehension, an independent search for the problem solution, an intensive cognitive interests' manifestation (Stupina, 2009).

The features of active learning include: forced thinking activation, when the learner forced to be active regardless of his/her desire; sufficiently long time of students' involvement in the educational process, since their activity should be stable and longlasting; presentation of the instructor as a training subject; independent decision-making by students; increase the degree of trainees' motivation; constant interaction of trainees and educators (Stupina, 2009). This learning form can include a seminar session, a seminar-discussion, and consultation. In these education forms, students show independence in educational and cognitive activities, resulting in deeper and more systematic knowledge.

\section{An interactive learning model}

Interactive ("Inter" is mutual, "act" is to act) means to interact, to be in the conversation mode, dialogue with someone. Unlike active methods, interactive students focus on a broader interaction, not only with the educator but also with each other and on the students' activity dominance in the learning process. The educator's place in interactive classes is reduced to the students' activities direction to achieve the lesson objectives. The educator also develops a lesson plan.

The factors that stimulate consider the students' activity include: cognitive and professional interest; creative nature of conducting classes; competitiveness; the game character of educational and cognitive activities; the emotional impact.

Among the main methodological principles of an interactive approach to teaching foreign languages are the following: mutual communication in a foreign language with the purpose of making and producing authentic information, equally interesting for all participants, in a situation that is important for all; joint activity, characterized by the interrelationship of three objects: the information producer, the information recipient and the situational

XLinguae, Volume 11, Issue 2, April 2018, ISSN 1337-8384, eISSN 2453-711X 
context; the transition to a democratic style of communication; reflective learning, conscious and critical comprehension of the action, its motives, qualities and results both from the teacher and students (Artamonova et al., 2012).

At the same time, the effectiveness of the learning process depends on the implementation of the principles:

1.Communicative-situational learning - provides the complex use of the communicative situations aimed at developing a foreign language.

2.Interactivity - implies that in the course of the learning process, postgraduates not only acquire educational and professionally significant knowledge and skills but also "change themselves as a result of their objective performance actions" (Artamonova, et al., 2012)

3.An integrated approach - is realized in the use of all types of speech activity.

4.Accounting for individual characteristics - the educator becomes freer in the choice of methodical techniques and various incentives that can support the motivation and mental activity during the entire period of learning (Badmaev,1999; Furmanov, 2003). 5.Variability of the working mode - involves the exchange of professionally relevant information in the group and individual levels, as well as a combination of lectures and assignment using modern means of communication.

6.Problems in learning means that "knowledge is not presented to the learner in a deterministic, completed form, intended only for memorization, but is given in the transition dynamics from ignorance to knowledge, with the active participation of the learners themselves in obtaining this knowledge as a result of independent work on the solution specially selected problems" (Dvulichanskaya, 2011).

Interactive learning allows you to develop the creative side of personality. The essence of interactive teaching methods is the orientation of the cognitive forces mobilization and the learners' aspirations, the awakening of an independent interest in cognition, the development of one's own activity modes, the development of the ability to concentrate on the creative process and to receive pleasure from it. Interactive methods refer to the subject experience and help learners in the knowledge process to get their own ways of discovering social experience (Nurutdinova et al., 2016a. Nurutdinova et al., 2016b).

The mandatory conditions for organizing interactive learning include:

- trust between the educator and the learners; reliance on personal experience of learners;

- cooperation in the communication process between the educator and learners who are learning among themselves;

- the variety of forms and methods of presenting information, the activity forms of educators, their mobility;

- the inclusion of external and internal motivation, as well as the mutual motivation (Bovtenko, 2005).

S.B. Barnes (2003), J.R. Young (2008) distinguish three interactive forms of interaction:

- interpersonal interactivity;

- informational interactivity;

- human-computer interaction in the information and communication environment.

The term "Interpersonal interactivity" means a bidirectional interaction between people, during which the recipient and the sender of messages can switch places and, being in an active position and interest, can make a successful act of communication. Interpersonal interactivity can include technology such as "Man-Man", which includes the following forms and methods of teaching: heuristic conversation; discussion; brainstorming; roleplaying games; training; presentations; case method; master classes and others. Use of information and communication technologies (ICT), such as interactive whiteboards, authentic and educational Internet resources, podcasts, wikis and blog technologies, and microblogging. 
"Information Interactive" is aimed at obtaining information and placing any information, including the use of Internet resources, search for data by keywords and other forms of interaction.

"Human-Computer Interactivity" or the interaction of a person with a computer is an area related to the interaction between the user and the computer's hardware and software, for example, through such devices and means of interaction as a mouse, keyboard, graphical interface, recognition of voice commands, and others.

Currently, in connection with the development of computer technologies and the possibilities of the Internet, the term "interactive learning" is increasingly used in the field of information technology, distance education, the use of Internet resources and work online. Thus, almost all learners have the opportunity to join each other in an interactive dialogue, written or oral, with a real partner in real time. There are active and passive user dialogues with the interactive software environment. With the active dialogue, the active interaction mode the user with the interactive learning environment, an equal relationship of its participants is established. Passive dialogue is another interaction mode between the user and the interactive learning environment. The dialogue initiative, in this case, belongs to the software environment leading the user, requiring him to make a decision providing additional information necessary for making adequate decisions. In the passive dialogue, the interactive tutorial software provides the user with information messages, hints and other comments that facilitate interaction with it. Requests to the user are usually built in the menus form or templates (Furmanov, 2003).

\subsection{The Teaching Approaches of ESL: Active Methods vs Interactive Methods}

The term "active methods and forms of learning" has long been used in the teaching of a foreign language. The active method is understood as the form of active interaction between the educator and learners, who in this case act not as passive listeners, but active participants in the class. Active learning methods are such teaching methods, in which the learners' activity is productive, creative, searching. At the same time learning turns into the arbitrary acts in the development and transformation of the experience. Two compulsory and interrelated requirements are imposed on active teaching methods:

1.they should promote the learners' activity in the educational process;

2.they must provide a deep understanding of the material being studied.

Learners cannot be active in the learning process if they don't understand the material being studied, but they won't be able to understand it without active inclusion in the learning process. These requirements play an important role not only in training but also in upbringing, as well as in the development of cognitive abilities of students. The choice of teaching methods for achieving goals and solving problems in the study of a foreign language is conditioned by the need to create communicative competence and a set of general cultural competencies that are necessary for the students to perform interpersonal interaction and cooperation in the conditions of intercultural communication, and to provide the required quality of instruction at all its stages.

This term unites a group of teaching technologies that achieve a high level of activity in the education activity of learners. However, it is worth noting that in the recent years the term "interactive learning" has also become widespread. At present, one of the key goals of the learning process has been the development of the learner personality and the increase in the activity degree. Thus, there is the need to create appropriate pedagogical technologies. There is a need to create learning conditions that are responsible for the learners' desire to obtain new results and successfully apply them in practice (Leontiev, 1991).

XLinguae, Volume 11, Issue 2, April 2018, ISSN 1337-8384, eISSN 2453-711X 
It should be noted that the identical sign is sometimes placed between active and interactive methods. However, despite the fact that these methods have some generality, they are still different from each other (Levitis, 1998).

An interactive teaching method can be considered as the most modern form of the active method. The concept of "interaction" (from English interaction - interaction) first arose in sociology and social psychology. In psychology, interaction refers to the interaction, the mutual influence of people or the impact of groups on each other as a continuous dialogue. In the social psychology (John Mead), direct interpersonal communication (the "exchange of symbols"), the most important feature of which is the persons' ability to "take the role of another", to imagine (feel) how he perceives the communication partner (or group).

Currently in pedagogy the concept of "interactive learning" is the cognition method of implemented in the forms of joint activity, all participants of the educational process interact with each other, exchange information, solve problems together, simulate situations, evaluate colleagues' actions and their own behaviour, immerse themselves in a real atmosphere of business cooperation to resolve problems (Stupina, 2009).

Thus, in the process of using interactive teaching methods, a learning environment is created that can be characterized by a large interaction of participants, the arguments equality, and the possibility of mutual evaluation and control. The goals of the interactive teaching method are as follows:

- increase the effectiveness of the educational process, achieve high results;

- strengthening the study motivation of the discipline;

- formation and development of professional skills;

- formation of communication skills;

- development of analytical skills and reflexive manifestations;

- development of skills in possession of modern technical means and technologies of perception and processing of information;

- ability formation and development of the independently find information and determine its reliability;

- reduction in the proportion of lectures and independent students' work (Artamonova et al., 2012).

The key concept defining the meaning of interactive methods is "interaction". Interaction is understood as the direct interpersonal communication, the most important feature of which is the ability of a person to "take the role of another", to imagine how the communication partner or group perceives it, and accordingly interpret the situation and design their own actions (Barnes, 2003).

According to the new Federal State Educational Standard of Higher Professional Education, both active and interactive forms should be used in the educational process (The Russian Federation Government Resolution dated April 9, 2010, № 218). This fact is yet another confirmation that the educational community shares these concepts.

However, it is necessary to clearly understand what lectures should be attributed to active, and which to interactive. It should be noted that in the State Federal Education Standard, types of educational activities, such as a lecture and seminar; the methods used in their conduct, are mixed (Federal Law № 273-FZ). It seems that such use is characterized by the form of conducting a lesson as a lecture.

The use of the interactive method in this type of educational activity is difficult since it involves the interaction of both the educator with learners and learners with each other (Nurutdinova, Dmitrieva, 2017).

Interactive teaching methods are based on direct contact between learners and the educators. Thus, the most appropriate use is to conduct practical exercises or seminars. The most popular forms of conducting such exercises include discussions, business and 
role games, brainstorming, training, case-method, employment in a game form. Interactivity in the class is characterized by replacing theoretical questions with practical tasks and solving problem situations. Students are modelled concrete situations, close to real. The students face a certain task - the need to resolve a particular problem. Thus, students are actively involved in the learning process.

One of the most popular forms of conducting interactive classes is the role-playing game, i.e., the game based on students performing certain role functions and actions that involve the decision adoption. Role-play involves imitating participants with behaviour corresponding to their role. The correctly organized role-playing game is the effective tool for developing decision-making skills.

One of the most effective ways of stimulating the creative activity is brainstorming, i.e. before the beginning, the educator forms a problem asks the learners the questions in order to obtain answers. In the lesson course, learners are considering possible options for problem solving. At the end, the educator and learners sum up the results and note the most creative ideas. The use of interactive methods in the learning process provides the teacher with the opportunity to solve the following problems: cognition orientation to all levels; the active learners' role; the internal source for learners' motivation; a fairly high percentage of knowledge assimilation (Polat, 2001; Sysoev, 2009; Borau, 2009).

The experience of many native and foreign educators testifies the effectiveness in using the interactive methods as one of the ways to develop intellectual abilities and critical thinking. The essence of interactive methods is to activate an independent cognitive interest and development of the ability to concentrate on the creative process and to receive satisfaction. Interactive methods are based on the personal experience.

The use of interactive methods in the learning process has several advantages. Lectures conducted in an interactive form, allow all learners to participate in active work, provide every student with the feasible participation in solving problems, and as a result, weaker leaners gain confidence, and the stronger ones, in turn, benefit for themselves, helping classmates to understand the material. In the working process in an interactive form, learners develop communication skills, the ability to cooperate and interact, develop critical thinking that is necessary for their future professional activity (Dvulichanskaya, 2011).

The development of interactive teaching methods in the education modernization is conditioned by the fact that not only the mastering leaners' knowledge and the formation of professional skills were set before the training, but also the development of the creative and communicative abilities, the formation of a personal approach to the emerging problem. Interactive methods are characterized by a greater interaction in the learning process, which allows interpreting interactive teaching methods as a modern form of active ones (Nurutdinova, Dmitrieva, 2018).

The main components of interactive lectures are interactive exercises and tasks that involve the active participation in the process. One of the most important differences between interactive tasks and ordinary ones is that, by performing them, learners not only understand the material already studied but also learn the new one in active interaction with the educator and with each other.

\section{Conclusions}

Modern trends in the world development are characterized by the use of new educational technologies in the English learning process. The education models are widely used in higher education include passive, active and interactive. Due to the requirements imposed on the learning process, in recent years active and interactive models have gained the most popularity. Many educators often equate active and interactive teaching methods.

XLinguae, Volume 11, Issue 2, April 2018, ISSN 1337-8384, eISSN 2453-711X 
However, interactive teaching methods are the modern interpretations of the old one. In the framework of active teaching methods, students actively interact with each other, while the educator plays the role of an "assistant" controlling the lesson course.

Interactive teaching methods are characterized by an even greater degree of activity since learners interact not only with each other but also with the teacher (Nurutdinova, Dmitrieva, 2017b). The learning forms in interactive methods include not only interpersonal interaction but also learning with the use of computer technology.

The widespread use of computers, multimedia technologies, and the Internet has had an impact on the education system, causing significant changes in the content and methods of teaching foreign languages.

The use of ICT in the educational process has the number of advantages: additional opportunities are created for the development of creative skills, increase interest in the scientific activity.

The use of ICT allows learners to work with teaching materials in various ways: learners themselves choose the way of studying, using interactive technical capabilities. The use of a computer makes it possible to optimize the learning process (Nurutdinova et al., 2016b).

In recent years, the new generation technologies Web 2.0 technologies have become widespread and the integral part in teaching a foreign language: using e-mail, wikitechnology, Skype, YouTube, various podcasts is popular than before. The educational blogs in the process of learning ESL creates settings for teaching learners to read and write. All this fully complies with the requirements of the modern educational standard on ESL.

One of the latest technologies for Web 2.0 is microblogging. Despite the relative novelty, its use is successfully introduced into the educational process, the didactic value is noted and recognized by many educators.

The use of microblogging in the process of ESL learning promotes the formation of communicative skills and is characterized by a high degree of learners' interaction through conversation in the form of dialogue or polylogue, which in turn is one of the ways to develop the communicative skills.

\section{Bibliographic references}

ARTAMONOVA, L.A. - ARKHIPOVA, M.V. - GANYUSHKINA, E.V. DELYAGIN, L.K. - ZOLOTOVA, M.V. - MARTYANOV, T.V. 2012. Innovations in teaching English to students of non-linguistic universities. In: Vestnik of Lobachevsky University of Nizhni Novgorod, vol. 2, n 1, pp. 28-33. ISSN: 1993-1778

BADMAEV, B.C. 1999. Methodology of teaching psychology: the teaching aids for teachers and graduate students of universities. Moscow: VLADOS. ISBN 5-69100259-7

BARNES, S.B. 2003. Computer-mediated communication: human to human communication across the Internet. London: Pearson. ISBN: 0205321453

BOVTENKO, M.A. 2005. Computer linguodidactics: a tutorial. Moscow: Science. ISBN: 5-89349-562-4.

DONETSKAYA, O.I. 2009. Internet technologies in teaching foreign languages: a teaching manual. Kazan: KSU. ISBN 978-5-98180-666-7.

DUDENEY, G. - HOCKLY, N. 2007. How to teach English with technology. Edinburgh: Longman. ISBN 978-1-4058-5308-8.

DVULICHANSKAYA, N.N. 2011. Interactive teaching methods as a means of key competencies formation. In: Science and Education Bauman MSTU, n. 4, pp. 345526. ISSN 1994-0408.

Federal Law № 273-FZ of December 29, 2012 “On Education in the Russian Federation". Available online : https://cyberleninka.ru/ar-ticle/n/the-law-oneducation-of-2012-and-development-of-educational-law-in-russia 
FURMANOV, M.A. 2003. Some aspects of the use of digital technologies in the teaching of foreign languages. In: Vestnik of Nizhny Novgorod Linguistics University, n. 3, pp. 217-223. ISSN: 2072-3490

GAL'SKOVA, N.D. 2001.Modern methods of teaching foreign languages. Moscow: AR KTI. ISBN 5-7695-2969-5.

GALUSHKIN, A.A. 2017a. Operational management of enterprise structures in the sphere of education and science: Problems and methods for their solution. In: European Research Studies Journal, vol. 20, n. 4, pp. 412-420. ISSN: 11082976.

GALUSHKIN, A.A. 2017b. Organizations of the sphere of education and science methods of competitiveness improvement. In: European Research Studies Journal, vol. 20, n. 4B, pp. 421-431. ISSN: 11082976.

GODWIN-JONES, R. 2003. Blogs and wikis: Environments for online collaboration. In: Language Learning \& Technology, vol. 7, n. 2, pp. 12-16. ISSN: 1094-3501.

KOROTAEVA, E.V. 2012. Some questions of interactive learning. In: Pedagogy, vol. 3, pp. 100-111. ISBN 0869-561X

LEONTIEV, A.A. 1991. General methodology of teaching foreign languages. Moscow: Russian language. ISBN: 5-200- 01080-2.

LEVITIS, D.G. 1998. The practice of teaching: modern educational technology. Moscow: Institute of Practice. ISBN 5-89395-075-5.

MASALIMOVA, A.R. - SHAIDULLINA, A.R. - USAK, M. 2016. Advantages and disadvantages of national and international corporate training techniques in adult education. In: Current Science (India), vol. 111, n 9, pp. 1480-1485. ISSN: 00113891.

NURUTDINOVA A.R. - ZAKIEVA Z.R. - ASTAFEVA A.E. - GALIULLINA E.I. DMITRIEVA E.V 2017. Awareness in acquisitive understanding of second language oral aspect: intercultural, socio-cultural and cross-cultural reflections. In: XLinguae, vol. 10, n. 4. pp. 69-83. ISSN: 1337-8384

NURUTDINOVA, A.R. - DMITRIEVA E.V. 2017. The problem of studying a second language in the development of the course "Academic English for graduate students". In" Herald of Vyatka State University, vol. 11, pp. 178-185. ISSN: 2541-7606

NURUTDINOVA, A.R. - DMITRIEVA E.V. 2018. The use of social network in the context of higher education: differences in learning outcomes between Moodle and Facebook. In: Modern problems of science and education, n. 1, 747-763. Available online: http://www.science-education.ru/ru/article/view?id=27380 ISSN 2070-7428

NURUTDINOVA, A.R. - DMITRIEVA, E.V. - GAZIZULINA, L.R. - TARASOVA, N.M. - GALIULLINA, E.I. 2016a. Nature and principles of the phenomenon of higher education integration: mechanisms of implementation, pros and cons, the effectiveness and the management. In: IEJME-Mathematics Education, vol. 11, n. 6, pp. 1697-1712. ISSN: 2468-4945.

NURUTDINOVA, A.R. - DMITRIEVA, E.V. 2016. Innovative ICT-based foreign language learning: evaluation techniques, assisted learning and foreign language teaching. In: The Bulletin of South Ural State University, Series «Linguistics», vol. 13, n. 3, pp. 4751. ISSN: 1991-9751.

NURUTDINOVA, A.R. - PERCHATKINA, V.G. - ZINNATULLINA, L.M. ZUBKOVA, G.I. - GALEEVA, F.T. 2016b. Innovation teaching practice: traditional and alternative methods. In: International Journal of Environmental and Science Education, vol. 11, n. 10, pp. 3807-3819. ISSN: 1306-3065.

ORDER OF THE MINISTRY OF EDUCATION AND SCIENCE OF THE RUSSIAN FEDERATION OF DECEMBER 19, 2013, № 1367. “On the approval of the Organization and implementation of educational activities on educational programs of higher education - bachelor's programs, speciality programs, master's programs". Available online: http://www.bukep.ru/assets/files/uch_rab/edu/02_bak/pr/gia/38_03_07_gia.pdf 
PASSOV, E.I. 1985. Communicative method of teaching foreign-speaking speaking: A manual for teachers of a foreign language. Moscow: Enlightenment. ISBN 5-200-010802.

POLAT, E.S. 2001. Internet in the lessons of foreign language. In: Foreign languages at school, n. 2, pp. 13-24. ISSN 0130-6073

QIU, L. - LEUNG, A. K. 2010. Understanding the Psychological Motives Behind Microblogging. Division of Psychology. Singapore: Nanyang Technological University. Available Online: http://www.ncbi.nlm.nih.gov/pubmed/20543286

SAMPLE, M. 2010. Practical advice for teaching with Twitter. In: The chronicle of higher education, n. 14, pp. 255-262. ISSN: 0009-5982.

SCHOLEFIELD, W. 1997. An overview of the teaching and learning of English in UCLA/URL. In: Babel, vol. 32, n. 1, pp. 16-38. ISSN: 0044-3328.

STUPINA, S.B. 2009. Interactive learning technologies in higher education school. Educational-methodical manual. Saratov: Science. ISBN 978-5-91272-909-6.

SYSOEV, P.V. 2009. Technologies Web 2.0: Social Wiki Service in Teaching Foreign Language. In: Foreign Languages in School, vol. 5, pp. 2-8. ISSN 0130-6073

SYSOEV, P.V. 2012. Modern information and communication technologies: didactic properties and functions. In: Language and culture, n. 1, pp. 120-133. ISSN: 1999-6195.

SYSOEV, P.V. 2016. Blog-technology in teaching a foreign language. In: Language and Culture, n. 4, pp. 115-127. ISSN: 1999-6195

THE RUSSIAN FEDERATION GOVERNMENT RESOLUTION DATED APRIL 9, 2010, № 218. “On measures of state support of development of cooperation of Russian higher education institutions and organizations implementing integrated projects for hightech industries".

THE RUSSIAN FEDERATION GOVERNMENT RESOLUTION DATED APRIL 9, 2010, № 219. “On state support of innovation infrastructure in the federal institutions of higher education". Available online: http://government.ru/docs/

THE RUSSIAN FEDERATION GOVERNMENT RESOLUTION DATED 9 APRIL 2010, № 220. “On measures to attract leading scientists at Russian institutions of higher education”. Available online: http://government.ru/docs/

THE RUSSIAN FEDERATION NATIONAL SECURITY STRATEGY UNTIL 2020. Approved by Presidential Decree of 12 May 2009, № 537. Available online: http://government.ru/docs/

TIKHOBAEV A.G. 2012. Interactive computer learning. In: Vestnik TGPU - Herald of Tomsk state pedagogical University, n. 8, pp. 81-84. ISSN 1609-624X

YOUNG, J.R. 2008. A professor's tips for using twitter in the classroom. Available online: http://chronicle.com/blogPost/A-Professor-s-Tips-for-Using/3643

ZAGVYAZINSKY, V.I. - ATAKHANOV R. 2005. Methodology and methods of psychological and pedagogical research. Textbook for students of higher pedagogical educational institutions. Moscow: Publishing Centre "Academy". ISBN: 5-76952146-5.

Words 8170

Characters: 56867 (31,59 standard pages)

Assoc. Prof. Aida Rustamovna Nurutdinova, PhD

Head of the Philology Department,

University of Management "TISBI"

13 Mushtari Str.

420012 Kazan

Russia

nurutdinova@my.com 
Assoc. Prof. Elena Viktorovna Dmitrieva, PhD

Department of Foreign Languages

Kazan State Power Engineering University

51 Krasnoselskaja Str.

420066 Kazan

Russia

elenadmitrieva75@yandex.ru

Assoc. Prof. Elena Anatolievna Nelyubina, PhD

Department of Linguistics and Foreign Languages

Kazan Branch of the Russian State University of Justice

7a The 2nd Azinskaya Str.

420088 Kazan

Russia

fekla@mail.ru

Assoc. Prof. Liliya Rashatovna Nurova, $\mathrm{PhD}$

Department of Linguistics and Foreign Languages

Kazan Branch of the Russian State University of Justice 7a The 2nd Azinskaya Str.

420088 Kazan

Russia

n_lika@list.ru

Assoc. Prof. Kira Rustemovna Wagner, PhD

Department of Linguistics and Foreign Languages

Kazan Branch of the Russian State University of Justice

7a The 2nd Azinskaya Str.

420088 Kazan

Russia

wak-2010@mail.ru 